\title{
A influência familiar na escolha da graduação dos estudantes de medicina da UEPA
}

\section{- Campus VIII - Marabá}

\author{
Family influence in the choice of undergraduate medical students at UEPA - Campus VIIII - \\ Marabá \\ Influencia de la familia en la elección profesional del estudiante de medicina de la UEPA - Campus \\ VIII - Marabá
}

Recebido: 20/06/2021 | Revisado: 27/06/2021 | Aceito: 28/06/2021 | Publicado: 12/07/2021

\author{
Gustavo Souza Araujo \\ ORCID: https://orcid.org/0000-0003-0758-542X \\ Universidade do Estado do Pará, Brasil \\ E-mail: gustavo.araujo@aluno.uepa.br \\ Gabriel Nunes da Silva \\ ORCID: https://orcid.org/0000-0002-1052-6511 \\ Universidade do Estado do Pará, Brasil \\ E-mail: gabrielnunessilva2011@ @otmail.com \\ Cilene Aparecida de Souza Melo \\ ORCID: https://orcid.org/0000-0003-1170-6466 \\ Universidade do Estado do Pará, Brasil \\ E-mail: gabrielnunessilva2011@ hotmail.com
}

\begin{abstract}
Resumo
Introdução: A importância da escolha profissional envolve os significados simbólicos e materiais, tendo reflexos durante toda ou boa parte da vida do indivíduo. Assim, reconhecendo a amplitude dos fatores motivacionais dessa escolha, esse estudo busca evidenciar e desvencilhar a influência do âmbito familiar nos graduandos do curso de medicina, tomando por amostras estudantes da UEPA - Marabá. Objetivo: Compreender a presença ou ausência de influência familiar na escolha pelo curso de medicina dos alunos da UEPA - Marabá, os seus aspectos influenciáveis e níveis de ocorrência. Metodologia: Trata-se de um estudo observacional, do tipo analítico transversal, com uso de questionário survey para identificar e avaliar os fatores familiares envolvidos na escolha profissional do estudante de Medicina residente de Marabá, com posterior montagem de tabelas e gráficos para análise dos resultados da pesquisa. Resultados: Constatouse através da apuração dos dados do questionário aplicado para 105 estudantes que há influência familiar determinante em uma parcela significativa dos estudantes, embora a maioria relativa tenha relatado o contrário. Conclusão: Concluise que há influência familiar nos acadêmicos de medicina da Universidade do Estado do Pará e que esta é multifatorial, com alguns aspectos se sobressaindo em relação a outros, entretanto, há a necessidade de mais estudos sobre a temática a fim de uma compreensão mais profunda sobre.
\end{abstract}

Palavras-chave: Escolha profissional; Relações familiares; Educação de graduação em medicina; Medicina; Ensino.

\begin{abstract}
Introduction: The importance of professional choice involves symbolic and material meanings, having reflections throughout all or a good part of an individual's life. Thus, recognizing the breadth of the motivational factors of this choice, this study seeks to highlight and untangle the influence of the family environment in medical students, taking samples from students from the Universidade do Estado do Pará (UEPA) - Marabá. Objective: To understand the presence or absence of family influence in the choice of the medical course of students at UEPA Marabá, its influential aspects and levels of occurrence. Methodology: This is an observational, analytical cross-sectional study, using a survey questionnaire to identify and evaluate the family factors involved in the professional choice of the medical student residing in Marabá, with subsequent assembly of tables and graphs to analyze the results of the research. Results: It was found through the verification of data from the questionnaire applied to 105 students that there is a decisive family influence in a significant portion of the students, although the relative majority reported the opposite. Conclusion: We conclude that there is a family influence on medical students at the University of the State of Pará and that this is multifactorial, with some aspects standing out in relation to others, however, there is a need for further studies on the subject in order to deepen understanding about.
\end{abstract}

Keywords: Career choice; Family relations; Undergraduate medical education; Medicine; Teaching. 


\section{Resumen}

Introducción: La importancia de la elección profesional implica significados simbólicos y materiales, teniendo reflejos durante toda o gran parte de la vida del individuo. Así, reconociendo la amplitud de los factores motivacionales de esta elección, este estudio busca resaltar y desenredar la influencia del entorno familiar en los estudiantes de medicina, tomando como muestra a estudiantes de UEPA - Marabá. Objetivo: Comprender la presencia o ausencia de influencia familiar en la elección de la facultad de medicina de los estudiantes de la UEPA - Marabá, sus aspectos influyentes y niveles de ocurrencia. Metodología: Se trata de un estudio observacional, analítico transversal, utilizando un cuestionario de encuesta para identificar y evaluar los factores familiares involucrados en la elección profesional del estudiante de medicina residente en Marabá, con posterior montaje de tablas y gráficos para analizar los resultados de la investigación. Resultados: Se encontró a través de la verificación de los datos del cuestionario aplicado a 105 estudiantes que existe una influencia familiar determinante en una porción significativa de los estudiantes, aunque la mayoría relativa refirió lo contrario. Conclusión: Se concluye que existe una influencia familiar en los estudiantes de medicina de la Universidad del Estado de Pará y que esta es multifactorial, destacando algunos aspectos sobre otros, sin embargo, se necesitan más estudios sobre el tema para una comprensión más profunda sobre.

Palabras clave: Elección profesional; Relaciones familiares; Educación médica de pregrado; Medicina; Enseñanza.

\section{Introdução}

A escolha de uma profissão possui um grande significado, visto que no sistema capitalista vigente o trabalho tem grande influência sobre acúmulo de bens, status, estilo de vida e suprimento de necessidades (Almeida \& Pinho, 2008; Coelho \& Matos, 2020). Sob o ponto de vista histórico e sociológico, o exercício laboral com o passar o tempo foi se associando fortemente ao poder aquisitivo, levando muitas profissões, especialmente as relacionadas com o domínio do conhecimento científico, a um patamar lógico de que todos que a exercem tem recursos financeiros, bom relacionamento social, bem como relevância humana para a sociedade. Nesse sentido, as universidades, se tornaram, gradativamente, o principal meio para capacitação da população, bem como o caminho para a ascensão social (Paletta et al., 2014).

Considerando o significado do trabalho e da sua relação científica na sociedade, surge o dilema da escolha da graduação, justificado pela abrangente influência na vida do sujeito, que passou a ver a profissão escolhida como o passaporte para o sucesso, assim profissões como as engenharias, direito e medicina passaram a ter uma visibilidade maior nesse cenário. Diante disso, deve-se levar em consideração os fatores envolvidos nessa escolha de extrema importância na vida do sujeito, pois aqui não estamos invalidando o fato de que muitos escolhem suas profissões com base em seus anseios, vocação, afinidade, convivência, estudo, interesse e visão de mundo, porém ressaltamos que esses mesmos sentimentos geralmente estão ligados a situações, impulsos, expectativas e até mesmo decepções familiares, sobretudo porque essa decisão costuma ocorrer durante ou logo após a adolescência, em uma fase observada e descrita por Bock (2007) como de transição e construção pessoal, na qual a família exerce papel fundamental (Almeida \& Pinho, 2008).

A família é um pilar fundamental da construção da mentalidade e personalidade de todo ser humano e cuja influência abrangente envolve variados aspectos de sua vivência, independentemente da formatação familiar, dentre os quais figura a tomada de decisões, estendendo-se até mesmo às menores delas. Consoante o que fora analisado por Almeida e Pinho (2008) no processo da escolha profissional, essa influência externa, de maneira velada ou aparente, produtiva ou não, se faz muito presente, desde a aprovação até ao projeto de vida expectado pelos pais, muitas vezes a custo de tensão nos laços familiares.

Motivação, no campo educacional, é um fenômeno complexo que abrange conotações diversas em relação ao direcionamento e a energia na aprendizagem. Existem várias características pertinentes à motivação no contexto educacional: (a) razões ou propósitos dos indivíduos para se engajarem numa atividade; (b) percepções da dificuldade e da capacidade para sua realização e (c) interesse pessoal e atribuições de valores pertinentes à atividade especifica onde as famílias tem um papel fundamental (Sousa et al., 2014). 
Outrossim, o curso de medicina figura em um cenário de muito prestígio e até mesmo supervalorização na cultura brasileira, esta que possui na família um dos seus principais meios de produção e disseminação, o que favorece a consolidação do curso como o mais concorrido no país. A isso atribui-se como causas prováveis o grande status e peso social, os quais também se relacionam à remuneração e ao mercado de trabalho (Nepomuceno \& Witter, 2010). Contudo, mesmo diante de pressões da família e da sociedade como um todo, as bases para uma profissão feliz e realizada devem estar fundamentadas na vocação do sujeito, consolidadas pelos seus projetos e objetivos de vida (Almeida \& Pinho, 2008; Coelho \& Matos, 2020). No âmbito da medicina, a vocação é imprescindível, sendo entendida como as virtudes necessárias ao correto e completo exercício médico tais como a empatia, prudência, prontidão, coragem, generosidade e zelo pela verdade e pela justiça na promoção de saúde pública (Bussad, 2006; Sousa et al., 2014).

Considerando essas informações, este estudo tem como objetivo geral compreender a influência que a família tem na escolha profissional do estudante de Medicina na UEPA - Marabá.

\section{Metodologia}

Trata-se de um estudo observacional do tipo analítico transversal com abordagem quantitativa, posto que foi feito um retrato da situação em questão, com a investigação das hipóteses dentro de uma população bem definida, tendo em mente a determinação da prevalência do fenômeno analisado entre os estudantes de medicina. A abordagem quantitativa na pesquisa atendeu às necessidades do estudo que foi feito, pois: houve o trabalho com uma grande amostragem de indivíduos; permitiu a utilização técnicas de coleta de dados que permitem uma análise e quantificação dos resultados rápidas; dispensava ambiguidades na interpretação dos dados coletados; impossibilitava a parcialidade do pesquisador na realização da pesquisa (Shitsuka, 2018). A pesquisa foi realizada entre setembro e outubro do ano de 2020 por meio da aplicação online de questionário survey a partir da plataforma Google Forms. A amostra consistiu de 105 alunos devidamente matriculados no curso de medicina do Campus VIII da UEPA (Universidade do Estado do Pará) no município de Marabá entre as turmas de 2015 a 2020 e seus períodos equivalentes, com margem de erro de 5\%. A fim de preservar a integridade individual de cada um dos participantes, não houve identificação dos seus nomes.

O questionário para coleta de dados foi elaborado com base na adaptação da Escala de Motivação Acadêmica (EMA), um instrumento consistente no contexto de investigação da motivação no ensino superior, permitindo níveis satisfatórios de consistência interna (Ribeiro, 2019). O questionário foi composto por 11 itens de caráter sociodemográfico e 11 afirmações objetivas para avaliação do nível de influência de diferentes fatores relacionados ao ambiente familiar na escolha profissional do estudante, conforme a correspondência entre vivências do discente e os enunciados apresentados na Escala de Likert. (Martinelli $\&$ Bartholomeu, 2007). No entanto, a presente pesquisa apenas avalia os aspectos familiares, que são definidos como externos ao indivíduo, desse modo, as asserções feitas foram do tipo "Eu já tive um parente negligenciado por um médico e isso me motivou a ser um e agir de maneira melhor”, de forma a verificar a presença da associação entre acontecimentos e/ou fatos familiares que envolvam o meio médico.

Os dados foram organizados, tabulados e convertidos em tabelas e gráficos a partir do programa Microsoft Excel®. As análises estatísticas descritivas foram realizadas usando o software R, versão 3.0.1 (R Development Core Team, 2020), visando maior transparência e qualidade na interpretação.

A pesquisa foi aprovada pelo Comitê de Ética em Pesquisa da Universidade do Estado do Pará sob o parecer de número 4.268.368 e CAEE de número 37228520.8.0000.8607. Os procedimentos desta pesquisa obedeceram aos Critérios da Ética na 
Pesquisa, conforme resolução No 466/12 do Conselho Nacional de Saúde - CNS, bem como conservou-se alinhado ao código de Nuremberg de 1949.

Para assegurar aos participantes seus direitos individuais e respeito ao seu bem-estar, sigilo e privacidade, o acesso ao questionário foi disponibilizado apenas após a leitura e confirmação da concordância do Termo de Consentimento Livre e Esclarecido (TCLE).

\section{Resultados}

Da população total de 141 pessoas, foram obtidas 105 respostas à aplicação online do questionário survey via Google Forms, o que corresponde a 74,4\% do corpo discente total (dados não apresentados em tabelas) e ao número amostral necessário para a realização do estudo. Levando em conta a necessidade de responder a todas as perguntas para que o questionário fosse computado, todos os questionamentos obtiveram suas respectivas respostas.

A Figura 1 diz respeito às médias de idade dos participantes agrupadas de acordo com o semestre que eles cursavam, a idade dos participantes variou de 18 a 36 anos, com média de 22,9 (desvio padrão = 3,8 anos). A maior média de idade observada foi no $11^{\circ}$ semestre, o que se esperava tendo em mente o avanço no curso, a qual teve valor de 31 anos (desvio padrão $=2,8$ anos), e a menor média obtida foi a dos estudantes do $3^{\circ}$ semestre, que foi estimada em 21,71 anos (desvio padrão $=3,5$ anos), inferior à obtida no $1^{\circ}$ semestre (média $=21,72$ anos).

Figura 1 - Média de idade dos participantes por semestre (em anos) no curso de medicina da Universidade do Estado do Pará em Marabá. Marabá, 2020.

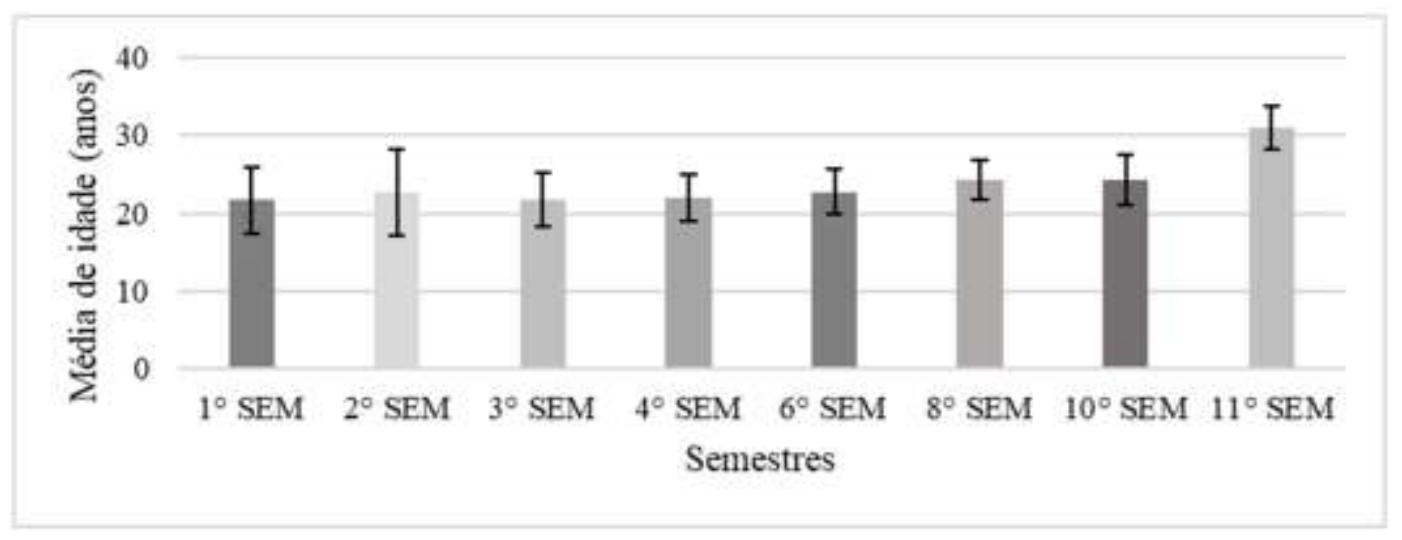

Fonte: Dados da pesquisa (2020).

Quanto ao quesito sexo, no qual apenas se consideraram os sexos biológicos, dos 105 discentes que participaram da pesquisa, 58 afirmaram pertencer ao sexo masculino $(55,24 \%)$ e 47 ao sexo feminino $(44,76 \%)$. Separando a contagem de sexo por semestre, pode-se observar a predominância do sexo masculino na maioria dos períodos do curso de Medicina (em 6 dos 8 semestres pesquisados, o sexo masculino aparecia como predominante ou ao menos com número igual ao do sexo oposto), conforme mostra a Figura 2. 
Figura 2 - Contagem de sexo por semestre no curso de medicina da Universidade do Estado do Pará em Marabá.

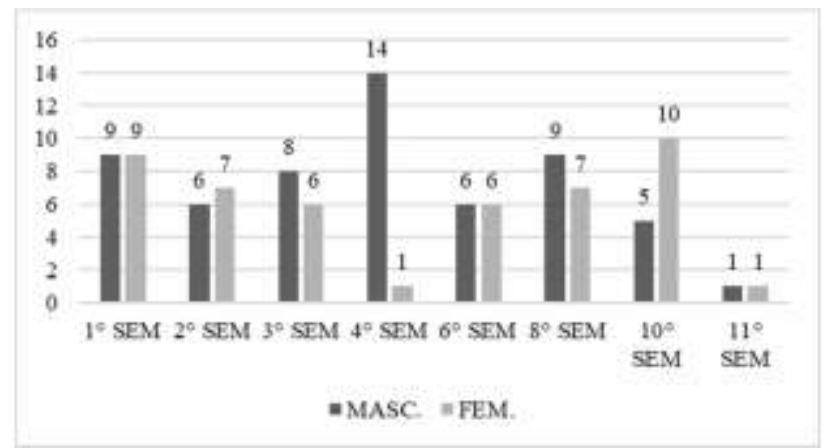

Fonte: Dados da pesquisa (2020).

No que diz respeito aos aspectos cor/etnia, estado civil e procedência, os dados foram agrupados em apenas uma tabela para melhor visualização, conforme mostrado na Tabela 1. Quanto à cor/etnia dos participantes, os dados foram divididos nos 3 ciclos de estudo do curso de medicina (ciclo básico, ciclo clínico e internato) para a melhor representação da realidade da universidade, tendo em vista a não presença de turmas em todos os semestres do curso em razão do antigo formato de abertura de apenas 1 turma de medicina por ano no campus de Marabá. Assim, o perfil de cor/etnia encontrado foi de predominância branca no curso de medicina da UEPA - Campus VIII $(44,87 \%)$ e na maioria dos ciclos de estudo (55\% no ciclo básico e 50\% no ciclo clínico), embora não houvesse respostas de brancos autodeclarados no internato, seguido de pardos (41,90\% do total de discentes) e negros (13,3\%), que representaram minoria em todos os ciclos avaliados e, consequentemente, no total analisado.

Ademais, tratando-se do estado civil dos participantes da pesquisa, constatou-se que, de um universo de 105 discentes, 92 eram solteiros $(87,6 \%), 11$ eram casados ou estavam em estado de união estável* $(10,4 \%)$ e, por fim, 2 (1,9\%) tinham o estado civil definido como outro (viúvo, separado, etc.).

Para a procedência dos discentes, avaliou-se que a maioria pertencia a outros municípios do interior do Pará* (44,76\%), seguidos de estudantes oriundos de Belém/Região metropolitana $(22,86 \%)$ ou residentes da própria cidade onde o curso é estabelecido - Marabá (22,86\%), com minoria de acadêmicos que vieram de fora do estado do Pará $(9,52 \%)$.

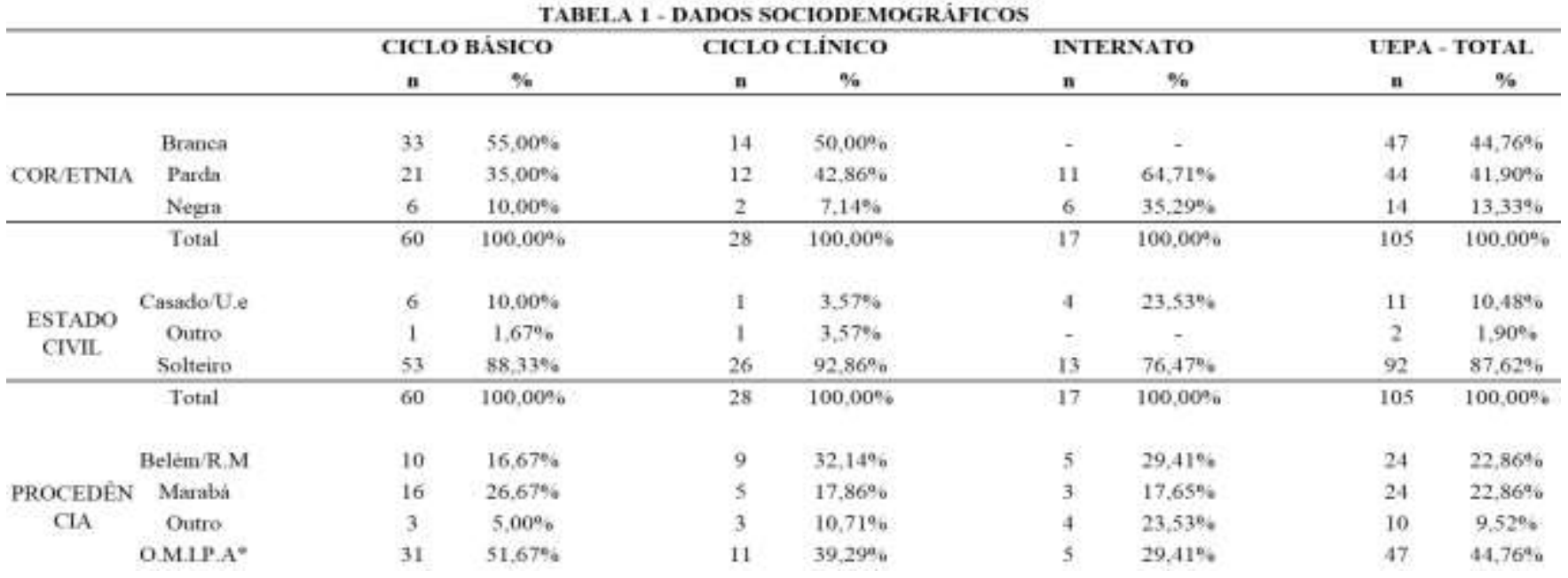

Fonte: Dados da pesquisa (2020). 
Em relação ao perfil econômico dos discentes participantes da pesquisa, novamente dividiu-se a totalidade do curso nos ciclos de estudos da graduação médica, trabalhando os aspectos de trabalho concomitante ao estudo, presença de outras graduações, escolaridade da mãe e do pai e, por fim, tipo de instituição onde cursou o ensino básico (particular ou pública), conforme mostra a Tabela 2. Com referência ao trabalho simultâneo à graduação de medicina, observou-se que a maioria dos graduandos não realizava atividade remunerada $(90,4 \%)$, com uma minoria realizando $(9,52 \%)$.

No que tange à presença de outros cursos no currículo do discente, a maioria afirmou que a medicina é o primeiro curso que entrou (66,67\%), seguido de acadêmicos que já haviam entrado em outras graduações, mas não concluíram (20,95\%), com minorias do total possuindo uma graduação, parte em outra área de atuação, isto é, fora da saúde (7,62\%), e parte na saúde $(4,76 \%)$.

Tratando-se da escolaridade dos pais, primeiro avaliou-se a escolaridade paterna, na qual as respostas foram agrupadas em três categorias para facilitar a compreensão: estudantes com pai que concluiu o ensino superior (26,67\%), estudantes que o pai possuía apenas o ensino básico completo (48,57\%) e estudantes com pai que não concluiu o ensino básico (24,76\%). Para a escolaridade materna, as mesmas três categorias foram consideradas no agrupamento: discentes que a mãe concluiu o ensino superior $(54,29 \%)$, discentes que a mãe concluiu apenas o ensino básico $(35,24 \%)$ e discentes que a mãe não concluiu o ensino básico $(10,48 \%)$.

No que se refere ao tipo de instituição que os acadêmicos cursaram o seu ensino básico, houve maioria absoluta de graduandos que cursaram em instituições particulares (52,38\%), seguidos de acadêmicos que tiveram o ensino básico em instituições públicas $(32,38 \%)$ e, por fim, estudantes que cursaram o ensino básico ora em uma instituição pública, ora em uma particular $(15,24 \%)$.

Tabela 2 - Dados econômicos.

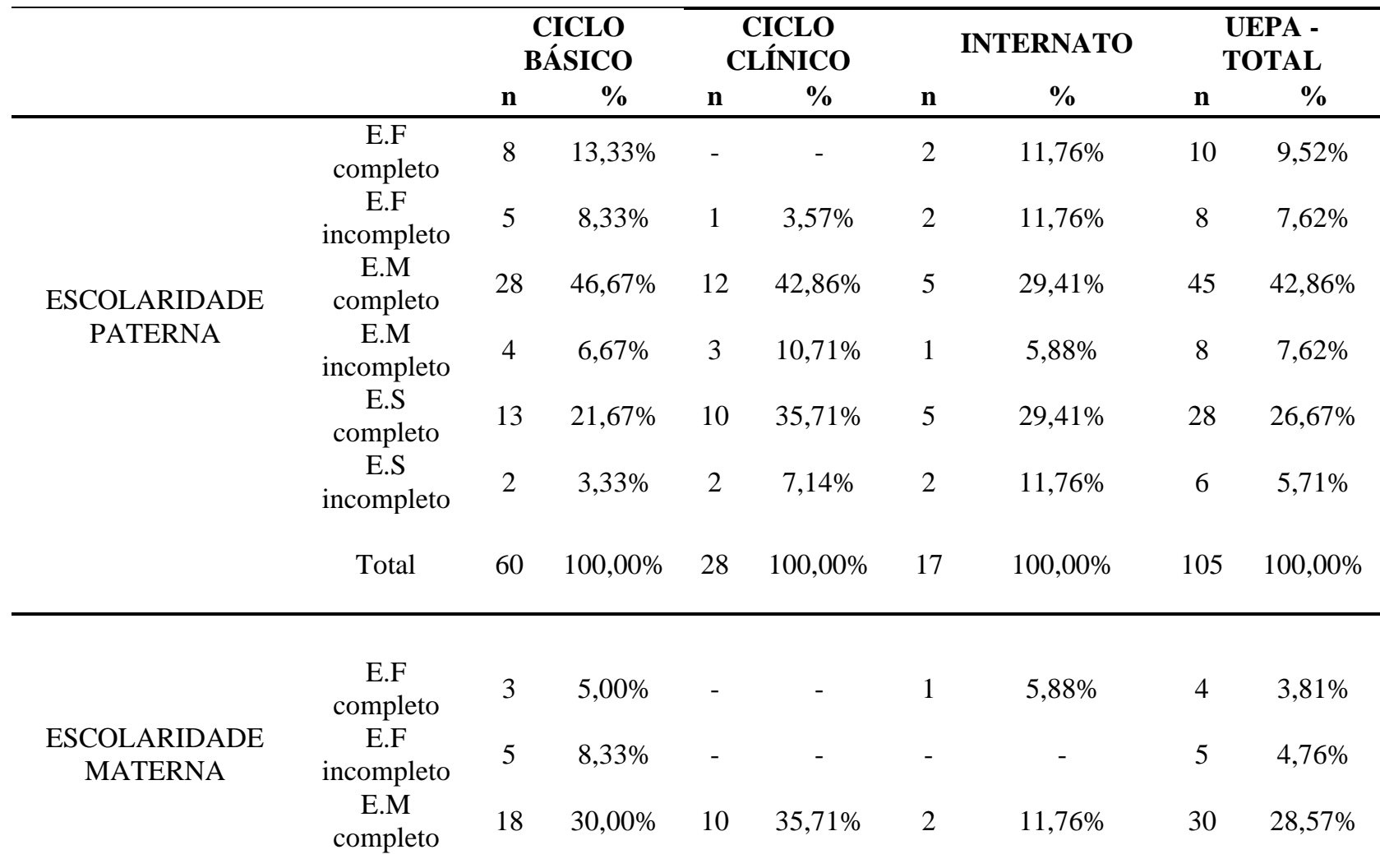




\begin{tabular}{ccccccccc}
$\begin{array}{c}\text { E.M } \\
\text { incompleto }\end{array}$ & 1 & $1,67 \%$ & 1 & $3,57 \%$ & - & - & 2 & $1,90 \%$ \\
$\begin{array}{c}\text { E.S } \\
\text { completo }\end{array}$ & 29 & $48,33 \%$ & 16 & $57,14 \%$ & 12 & $70,59 \%$ & 57 & $54,29 \%$ \\
$\begin{array}{c}\text { E.S } \\
\text { incompleto }\end{array}$ & 4 & $6,67 \%$ & 1 & $3,57 \%$ & 2 & $11,76 \%$ & 7 & $6,67 \%$ \\
Total & 60 & $100,00 \%$ & 28 & $100,00 \%$ & 17 & $100,00 \%$ & 105 & $100,00 \%$ \\
\hline & & & & & & & & \\
Particular & 22 & $36,67 \%$ & 18 & $64,29 \%$ & 15 & $88,24 \%$ & 55 & $52,38 \%$ \\
Pública & 25 & $41,67 \%$ & 9 & $32,14 \%$ & - & - & 34 & $32,38 \%$ \\
Part/Pub & 13 & $21,67 \%$ & 1 & $3,57 \%$ & 2 & $11,76 \%$ & 16 & $15,24 \%$ \\
& & & & & & & & \\
Total & 60 & $100,00 \%$ & 28 & $100,00 \%$ & 17 & $100,00 \%$ & 105 & $100,00 \%$
\end{tabular}

\begin{tabular}{cccccccccc}
\hline TRABALHA E & Não & 53 & $88,33 \%$ & 27 & $96,43 \%$ & 15 & $88,24 \%$ & 95 & $90,48 \%$ \\
ESTUDA? & Sim & 7 & $11,67 \%$ & 1 & $3,57 \%$ & 2 & $11,76 \%$ & 10 & $9,52 \%$ \\
& Total & 60 & $100,00 \%$ & 28 & $100,00 \%$ & 17 & $100,00 \%$ & 105 & $100,00 \%$ \\
\hline
\end{tabular}

\begin{tabular}{|c|c|c|c|c|c|c|c|c|c|}
\hline \multirow{6}{*}{$\begin{array}{c}\text { POSSUI } \\
\text { OUTRAS } \\
\text { GRADUAÇÕES? }\end{array}$} & $\begin{array}{c}\text { Não, esse é } \\
\text { o meu } \\
\text { primeiro } \\
\text { curso do } \\
\text { ensino } \\
\text { superior }\end{array}$ & 38 & $63,33 \%$ & 19 & $67,86 \%$ & 13 & $76,47 \%$ & 70 & $66,67 \%$ \\
\hline & & & & & & & & & \\
\hline & $\begin{array}{l}\text { Não, mas } \\
\text { cheguei a } \\
\text { entrar em } \\
\text { outro curso }\end{array}$ & 13 & $21,67 \%$ & 7 & $25,00 \%$ & 2 & $11,76 \%$ & 22 & $20,95 \%$ \\
\hline & $\begin{array}{l}\text { Sim, mas } \\
\text { em outra } \\
\text { área de } \\
\text { atuação }\end{array}$ & 7 & $11,67 \%$ & - & - & 1 & $5,88 \%$ & 8 & $7,62 \%$ \\
\hline & $\begin{array}{l}\text { Sim, na área } \\
\text { da saúde }\end{array}$ & 2 & $3,33 \%$ & 2 & $7,14 \%$ & 1 & $5,88 \%$ & 5 & $4,76 \%$ \\
\hline & Total & 60 & $100,00 \%$ & 28 & $100,00 \%$ & 17 & $100,00 \%$ & 105 & $100,00 \%$ \\
\hline
\end{tabular}

Fonte: Dados da pesquisa (2020).

Sobre o questionário com as questões específicas para a influência familiar na escolha de medicina do acadêmico, os dados sobre as principais questões foram organizados na Tabela 3. Quanto ao primeiro questionamento, que dizia "Um parente meu passou por uma experiência ruim com um médico e isso me influenciou a ser um e ser melhor", do universo de 105 estudantes, a maioria absoluta respondeu que discordava totalmente ou apenas discordava $(51,43 \%)$, seguida de acadêmicos que concordavam totalmente ou só concordavam $(31,43 \%)$, com uma minoria de participantes não concordando nem discordando $(17,14 \%)$.

Seguindo a ordem das questões propostas, a maioria relativa dos participantes da pesquisa concordava totalmente ou apenas concordava que a situação econômica da família influenciava na escolha pela medicina, tendo em vista o bom retorno 
financeiro $(43,81 \%)$. Ademais, uma parcela significativa discordava totalmente ou discordava que a situação financeira familiar havia tido influência (36,19\%), e uma minoria não concordava nem discordava (20,00\%).

Com relação ao grande prestígio da profissão médica no meio familiar e a influência desse fator na escolha do participante, a maioria concordava totalmente ou concordava $(45,71 \%)$, seguida de pessoas que discordavam totalmente ou apenas discordavam $(35,24 \%)$, com poucos não concordando nem discordando com o enunciado proposto $(19,05 \%)$.

No que diz respeito ao fato de a família afirmar desde a infância que o participante seria médico, a maioria absoluta dos pesquisados discordava totalmente ou discordava $(68,57 \%)$, quase um terço do total concordava totalmente ou apenas concordava $(23,81 \%)$, e uma minoria não concordava nem discordava $(7,62 \%)$.

A respeito de indicações da família que o curso de medicina deveria ser escolhido no ano de vestibular, a maioria absoluta dos participantes discordava ou discordava totalmente $(60,00 \%)$, ao passo que parcelas significativamente menores concordavam totalmente ou concordavam $(23,81 \%)$ ou não concordavam nem discordavam $(16,19 \%)$.

Acerca de a possibilidade de poder cuidar da saúde da família por cursar medicina ser uma grande inspiração para a escolha de curso, a maioria absoluta dos graduandos concordava ou concordava totalmente $(70,48 \%)$, uma pequena fração não concordava nem discordava $(14,29 \%)$, e uma minoria discordava totalmente ou discordava $(15,24 \%)$.

No que concerne ao enunciado de "de fato, a minha família influenciou a minha decisão pelo curso de medicina", as duas maiores parcelas de alunos responderam que concordavam totalmente/concordavam $(41,91 \%)$ ou discordavam totalmente/discordavam (45,72\%), ao passo que uma minoria do total afirmou não concordar nem discordar (12,38\%).

Tratando sobre a influência na decisão do acadêmico pela presença de um familiar profissional da saúde, nos 3 ciclos de estudo, a maioria absoluta dos participantes respondeu discordo totalmente/discordo (69,52\%), com mínimas respostas diferentes (dados não dispostos em tabelas).

Tabela 3 - Dados sobre o questionário da influência familiar.

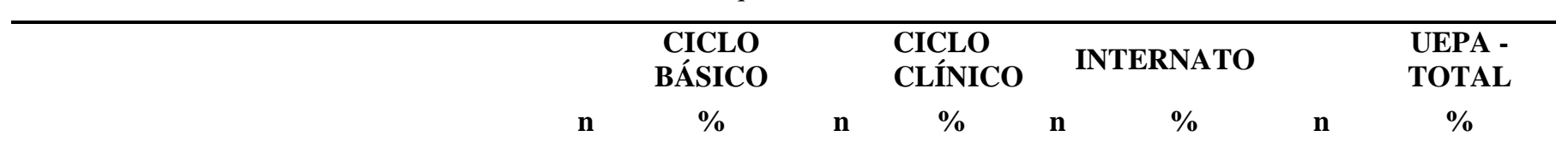

Um parente meu passou por uma experiência ruim com um médico e isso me influenciou a ser um e ser melhor

\begin{tabular}{ccccccccc}
\hline 1 - Discordo totalmente & 30 & $50,00 \%$ & 5 & $17,86 \%$ & 2 & $11,76 \%$ & 37 & $35,24 \%$ \\
2 - Discordo & 7 & $11,67 \%$ & 6 & $21,43 \%$ & 4 & $23,53 \%$ & 17 & $16,19 \%$ \\
3 - Não concordo nem discordo & 8 & $13,33 \%$ & 9 & $32,14 \%$ & 1 & $5,88 \%$ & 18 & $17,14 \%$ \\
4 - Concordo & 10 & $16,67 \%$ & 4 & $14,29 \%$ & 8 & $47,06 \%$ & 22 & $20,95 \%$ \\
5 - Concordo totalmente & 5 & $8,33 \%$ & 4 & $14,29 \%$ & 2 & $11,76 \%$ & 11 & $10,48 \%$ \\
\hline Total & 60 & $100,00 \%$ & 28 & $100 \%$ & 17 & $100,00 \%$ & 105 & $100,00 \%$
\end{tabular}

A situação econômica da minha família me fez optar pela Medicina, pois o retorno financeiro é bom

$\begin{array}{ccccccccc}\text { 1 - Discordo totalmente } & 13 & 21,67 \% & 8 & 28,57 \% & 1 & 5,88 \% & 22 & 20,95 \% \\ 2 \text { - Discordo } & 10 & 16,67 \% & 3 & 10,71 \% & 3 & 17,65 \% & 16 & 15,24 \% \\ 3 \text { - Não concordo nem discordo } & 14 & 23,33 \% & 4 & 14,29 \% & 3 & 17,65 \% & 21 & 20,00 \%\end{array}$




\begin{tabular}{ccccccccc} 
4 - Concordo & 13 & $21,67 \%$ & 10 & $35,71 \%$ & 7 & $41,18 \%$ & 30 & $28,57 \%$ \\
5 - Concordo totalmente & 10 & $16,67 \%$ & 3 & $10,71 \%$ & 3 & $17,65 \%$ & 16 & $15,24 \%$ \\
\hline Total & 60 & $100,00 \%$ & 28 & $100 \%$ & 17 & $100,00 \%$ & 105 & $100,00 \%$
\end{tabular}

Na minha família, a profissão médica é muito prestigiada e isso me influenciou a ser um

\begin{tabular}{ccccccccc}
\hline 1 - Discordo totalmente & 13 & $21,67 \%$ & 5 & $17,86 \%$ & 2 & $11,76 \%$ & 20 & $19,05 \%$ \\
2 - Discordo & 10 & $16,67 \%$ & 6 & $21,43 \%$ & 1 & $5,88 \%$ & 17 & $16,19 \%$ \\
3 - Não concordo nem discordo & 14 & $23,33 \%$ & 3 & $10,71 \%$ & 3 & $17,65 \%$ & 20 & $19,05 \%$ \\
4 - Concordo & 13 & $21,67 \%$ & 10 & $35,71 \%$ & 11 & $64,71 \%$ & 34 & $32,38 \%$ \\
5 - Concordo totalmente & 10 & $16,67 \%$ & 4 & $14,29 \%$ & 0 & $0,00 \%$ & 14 & $13,33 \%$ \\
\hline Total & 60 & $100,00 \%$ & 28 & $100 \%$ & 17 & $100,00 \%$ & 105 & $100,00 \%$
\end{tabular}

Minha família sempre disse para os outros que eu seria médico, desde a escola

\begin{tabular}{ccccccccc}
\hline 1 - Discordo totalmente & 28 & $46,67 \%$ & 11 & $39,29 \%$ & 9 & $52,94 \%$ & 48 & $45,71 \%$ \\
2 - Discordo & 11 & $18,33 \%$ & 6 & $21,43 \%$ & 7 & $41,18 \%$ & 24 & $22,86 \%$ \\
3 - Não concordo nem discordo & 7 & $11,67 \%$ & 1 & $3,57 \%$ & 0 & $0,00 \%$ & 8 & $7,62 \%$ \\
4 - Concordo & 10 & $16,67 \%$ & 7 & $25,00 \%$ & 1 & $5,88 \%$ & 18 & $17,14 \%$ \\
5 - Concordo totalmente & 4 & $6,67 \%$ & 3 & $10,71 \%$ & 0 & $0,00 \%$ & 7 & $6,67 \%$ \\
\hline Total & 60 & $100,00 \%$ & 28 & $100 \%$ & 17 & $100,00 \%$ & 105 & $100,00 \%$
\end{tabular}

Poder cuidar melhor da saúde dos meus familiares foi uma grande inspiração para minha escolha de curso

\begin{tabular}{ccccccccc}
\hline 1 - Discordo totalmente & 4 & $6,67 \%$ & 1 & $3,57 \%$ & 2 & $11,76 \%$ & 7 & $6,67 \%$ \\
2 - Discordo & 6 & $10,00 \%$ & 3 & $10,71 \%$ & 0 & $0,00 \%$ & 9 & $8,57 \%$ \\
& & & & & & & & \\
3 - Não concordo nem discordo & 8 & $13,33 \%$ & 6 & $21,43 \%$ & 1 & $5,88 \%$ & 15 & $14,29 \%$ \\
& & & & & & & & \\
4 - Concordo & 25 & $41,67 \%$ & 8 & $28,57 \%$ & 12 & $70,59 \%$ & 45 & $42,86 \%$ \\
5 - Concordo totalmente & 17 & $28,33 \%$ & 10 & $35,71 \%$ & 2 & $11,76 \%$ & 29 & $27,62 \%$ \\
\hline Total & & & & & & & & \\
\hline
\end{tabular}

De fato, a minha família influenciou a minha decisão pelo curso de Medicina

$\begin{array}{ccccccccc}\text { 1 - Discordo totalmente } & 19 & 31,67 \% & 8 & 28,57 \% & 2 & 11,76 \% & 29 & 27,62 \% \\ 2 \text { - Discordo } & 11 & 18,33 \% & 4 & 14,29 \% & 4 & 23,53 \% & 19 & 18,10 \% \\ & & & & & & & & \\ 3 \text { 3 - Não concordo nem discordo } & 6 & 10,00 \% & 5 & 17,86 \% & 2 & 11,76 \% & 13 & 12,38 \%\end{array}$




\begin{tabular}{ccccccccc} 
4 - Concordo & 19 & $31,67 \%$ & 4 & $14,29 \%$ & 6 & $35,29 \%$ & 29 & $27,62 \%$ \\
5 - Concordo totalmente & 5 & $8,33 \%$ & 7 & $25,00 \%$ & 3 & $17,65 \%$ & 15 & $14,29 \%$ \\
\hline Total & 60 & $100,00 \%$ & 28 & $100 \%$ & 17 & $100,00 \%$ & 105 & $100,00 \%$
\end{tabular}

No ano de vestibular, meus pais e/ou responsáveis disseram que eu deveria escolher Medicina nas opções de curso

\begin{tabular}{|c|c|c|c|c|c|c|c|c|}
\hline 1 - Discordo totalmente & 23 & $38,33 \%$ & 12 & $42,86 \%$ & 4 & $23,53 \%$ & 39 & $37,14 \%$ \\
\hline 2 - Discordo & 11 & $18,33 \%$ & 4 & $14,29 \%$ & 9 & $52,94 \%$ & 24 & $22,86 \%$ \\
\hline 3 - Não concordo nem discordo & 10 & $16,67 \%$ & 6 & $21,43 \%$ & 1 & $5,88 \%$ & 17 & $16,19 \%$ \\
\hline 4 - Concordo & 9 & $15,00 \%$ & 5 & $17,86 \%$ & 3 & $17,65 \%$ & 17 & $16,19 \%$ \\
\hline 5 - Concordo totalmente & 7 & $11,67 \%$ & 1 & $3,57 \%$ & 0 & $0,00 \%$ & 8 & $7,62 \%$ \\
\hline Total & 60 & $100,00 \%$ & 28 & $100 \%$ & 17 & $100,00 \%$ & 105 & $100,00 \%$ \\
\hline
\end{tabular}

\section{Discussão}

Os resultados desse estudo descrevem a influência familiar na escolha profissional do estudante de Medicina da Universidade do Estado do Pará (UEPA), campus de Marabá, além de caracterizarem seu perfil sociodemográfico e econômico, dados que serão usados para a presente discussão, a qual será sistematizada em 5 eixos: aspectos sociodemográficos e econômicos do estudante de medicina, influência da presença de familiar profissional da saúde, influência de incentivos diretos da família, influência de experiências médicas ruins no seio familiar e influência da situação socioeconômica da família do estudante. Para a discussão dos dados obtidos, consideramos como afirmativas as respostas "concordo totalmente" e "concordo", como negativas as respostas "discordo" e "discordo totalmente" e como neutras as respostas "não concordo e nem discordo", conforme será observado a seguir.

O questionário sociodemográfico revelou que a média de idade dos participantes era de 22,9 anos (desvio padrão = 3,8 anos), dado que se assemelha aos achados em universidades de medicina das regiões sudeste e nordeste do país e que revela o padrão etário na graduação de uma maneira geral. Com relação ao sexo dos participantes, observou-se maioria de estudantes do sexo masculino, o que está em concordância com os dados achados em um curso de Medicina da mesma região (Rego, 2018), mas que se contrapõe à maioria feminina vista em uma universidade de Medicina da região sudeste (Souza et al., 2020), o que revela o retardo do processo de feminização da Medicina descrito por outros autores (Scheffer \& Cassenote, 2013) no norte brasileiro em comparação ao sudeste, realidade que pode se dar em razão das disparidades socioeconômicas entre as diferentes regiões brasileiras. Sobre a raça/etnia predominante, houve maioria branca no caso do campus de Marabá da UEPA e em uma universidade da região sudeste do país, ao passo que a universidade localizada no nordeste brasileiro apresentou predominância de pessoas pardas (Veras et al., 2020; Souza et al., 2020)

Com relação à procedência dos acadêmicos de Medicina da UEPA, houve predominância de pessoas vindas do próprio estado do Pará, achado estatístico que entra em concordância com o visto em uma universidade da região nordeste do Brasil, no qual a maioria dos estudantes vinha do próprio estado de localização da universidade, o que pode se dar em razão da comodidade 
de se cursar medicina no estado de origem, mas, no caso da UEPA, há, também, a presença de cotas protecionistas que valorizam a nota de vestibulandos que moram no Pará há certo tempo (Veras et al., 2020). Outrossim, houve a descrição do estado civil dos acadêmicos, na qual a maioria absoluta descreveu ser solteira, fato que pode estar relacionado à falta de tempo livre para outras atividades fora o estudo, conforme descrito por outros autores (Benevides-Pereira \& Gonçalves, 2009)

O questionário econômico descreveu que a maioria dos graduandos em Medicina da UEPA não realizava atividade econômica remunerada, o que deve ser resultado do extenso currículo do curso, o que, por vezes, faz com que a única atividade dos estudantes seja o estudo pela falta de tempo livre, estatística que está em conformidade com as vistas em uma universidade localizada no Rio de Janeiro (Souza et al., 2020). No que tange à presença de graduações anteriores, a maioria dos estudantes afirmou que Medicina se tratava do primeiro curso de ensino superior, dado que acompanha as estatísticas encontradas em universidades de outras regiões do país (Veras et al., 2020), o que, associado às informações sobre a realização de atividade remunerada pelos estudantes, revela que boa parte dos graduandos de Medicina depende de alguma influência econômica externa para se manter no curso e, também, implica que alguma parcela dos acadêmicos se encontra em situação de vulnerabilidade socioeconômica, retrato que também foi observado por outros autores (Veras et al., 2020).

Tratando da escolaridade dos pais, observou-se que o grau de instrução das mães dos estudantes foi maior do que o dos pais, estatísticas que estão de acordo com as achadas em outras pesquisas sociodemográficas feitas com estudantes de Medicina de universidades da região norte e sudeste do país (Souza et al., 2020; Rego et al., 2018). Esse cenário se relaciona com a crescente entrada de mulheres no meio acadêmico que acontece desde o século passado, conforme descrito por uma análise do retrato nacional (Guedes, 2008), e corrobora o fato de que cada vez mais mulheres se formam em relação aos homens.

No que tange ao tipo de instituição que os acadêmicos fizeram seu ensino básico, houve predominância de participantes que cursaram em instituições privadas, o que vai ao encontro de outros estudos feitos com acadêmicos de Medicina (Veras et al., 2020; Souza et al., 2020) e, com esse achado estatístico, há a descrição do perfil sociodemográfico e econômico geral do estudante de Medicina: pessoas brancas, que cursaram o ensino básico em instituições privadas, que dependem de suporte econômico externo para se manterem e estão na sua primeira graduação. Esse perfil apenas comprova que o curso de Medicina se trata de um curso altamente elitista, composto majoritariamente por pessoas brancas e vindas de escolas particulares, as quais oferecem uma qualidade de ensino superior às públicas em troca de condições econômicas favoráveis.

O questionamento específico para a influência de profissionais da saúde na família na escolha profissional dos acadêmicos revelou que a maioria absoluta discordava totalmente ou discordava, o que revela que, apesar de Lisboa (1997) descrever que a identidade ocupacional, isto é, como uma pessoa integra suas diferentes identificações e sabe a atividade que quer desempenhar, a maneira e em que cenário (Bohoslavsky, 1997/1998), forma-se através da autopercepção que a pessoa tem dos papéis profissionais com os quais ela tem contato, principalmente com figuras significativos, como pais e familiares, o processo de construção dessa identidade não foi influenciado pelo contato com familiares profissionais da saúde dado o alto nível de rejeição ao questionamento feito, o que pode ter acontecido por um possível convívio ínfimo, que não proporcionou tempo necessário para que o acadêmico se identificasse com a área de atuação, nesse caso, a saúde, do seu familiar, mas que também pode ter sido causado pela não existência de profissionais da área da saúde na família dos participantes.

Ademais, a literatura nacional pouco aborda a influência de familiares com determinada profissão na escolha profissional de vestibulandos dentro do seio familiar, o que não permite conclusões mais profundas acerca do assunto. Assim, percebe-se a necessidade da realização de mais estudos nessa área de pesquisa a fim de desenvolvê-la suficientemente a ponto de aumentar a compreensão sobre o processo de construção da identidade ocupacional e, consequentemente, da escolha profissional que acontecerá. 
Os dados estatísticos apurados em duas perguntas do questionário específicas para os incentivos diretos ("Minha família sempre disse para os outros que eu seria médico, desde a escola" e "No ano de vestibular, meus pais e/ou responsáveis disseram que eu deveria escolher Medicina nas opções de curso") revelaram que a maioria absoluta dos estudantes não teve incentivos diretos para a escolha da graduação em Medicina no ano de vestibular, fato que apenas significa que não houve encorajamento ao curso de Medicina, o que, portanto, não indica que não houve influência desse tipo para outros cursos, porém tal possibilidade não cabe ser discutida aqui. Filomeno (1967) descreve sobre a existência de mito familiar, o qual, para Krom (2000), "constitui em sua essência a concepção de mundo própria da família, onde se cria a realidade familiar e o mapa do mundo individual”, que, no caso dos graduandos em Medicina, podem ter sido manifestados no encorajamento para outras direções profissionais desde a infância e durante o período de vestibular e, ao escolher a graduação médica, o discente poderia estar confrontando ou transformando tal mito familiar, conforme descrito por Filomeno (1967).

Contudo, para a discussão mais profunda dessa temática, há a necessidade de mais estudos na área, tendo em vista as limitações desse estudo, que é descritivo e quantitativo.

Constatou-se também, a presença da influência a partir de experiências negativas vividas por familiares no meio médico em aproximadamente um terço dos estudantes. Carvalho (2017) identificou esse fenômeno como "catarse", visto que experiências traumáticas vividas ou ouvidas de familiares podem permanecer emocionalmente na consciência, não apenas inativamente, mas potencialmente capazes de interferir, em algum grau, opiniões e decisões.

Essa denominação é corroborada por Gomes (2005), na medida em que o desejo revelado pelos participantes em exercer medicina objetivando impedir a repetição desses traumas a seus familiares ou a outras pessoas exemplifica um mecanismo de remissão de emoções negativas aplicado socialmente.

Foi possível observar que cerca de 1 em cada 3 participantes consideram que a situação econômica da família o fez optar pela Medicina, considerando o retorno financeiro e que aproximadamente $45 \%$ foi influenciado pelo prestígio do curso no ambiente familiar. Isso se explica porque o indivíduo, ao escolher a profissão, leva em consideração a sua adequação ao mercado de trabalho e o retorno financeiro, de modo que, de acordo com Souza (2018) e Carvalho (2017), condiciona a liberdade de escolha pela pressão econômica (Oliveira, 2017).

Essa pressão não se aplica isoladamente, mas está associada intrinsecamente ao status e ascensão social, uma vez que revela o comprometimento com a própria identidade pessoal e a necessidade, definida pela estrutura social vigente, de alcançar esse estado (Santos, 2005; Souza, 2018, Oliveira, 2017, Carvalho, 2017).

Correa et al (2016) corrobora essas afirmações ao constatar esses fatores na vida de estudantes que cursavam medicina na Universidade Federal de Minas Gerais (MG) após terem iniciado ou terminado outra graduação, indicando que essa influência pode determinar a busca por ascensão socioeconômica por meio da desistência de outras formações acadêmicas e do subsequente ingresso na formação médica.

Portanto, tornar-se médico é uma oportunidade de "superar a situação social no qual a família se encontra" e "cumprir com a sua missão não apenas individual, mas familiar" (Santos, 2005, p.59).

\section{Conclusão}

Concluímos que há influência familiar na escolha pelo curso de medicina em parcela significativa dos acadêmicos da UEPA-Marabá, a qual é multifatorial, abrangendo diversos aspectos socioculturais e econômicos da vida do indivíduo e de seus familiares, alguns sobressaindo-se sobre outros. Os instrumentos utilizados permitiram a verificação e elucidação de diferentes 
fatores de influência e estabelecimento de eixos de abordagem. Observou-se que experiências familiares negativas com o meio médico e condição socioeconômica da família do discente contribuíram na escolha de significativa parcela dos estudantes, enquanto que a presença de familiares profissionais de saúde e incentivos diretos da família apresentaram baixa ou nenhuma influência na maioria dos discentes. Verificou-se também que essa influência não se demonstra homogênea entre os estudantes, haja vista que algumas das respostas ao questionário revelaram significativas divergências de opinião. O presente estudo não pretende exaurir o tema, pelo contrário, sugerimos a execução de mais pesquisas para o seu aprofundamento, tendo em mente a ínfima abordagem da temática na atualidade, o que dificultou o embasamento teórico atual para o presente estudo, bem como as limitações teóricas da pesquisa realizada que, por ser quantitativa, apenas avalia aspectos gerais sem se aprofundar em características subjetivas, limitando uma compreensão mais profunda a respeito do assunto abordado. Para isso, aconselhamos que os próximos estudos a serem realizados tenham abordagens qualitativas, objetivando uma perspectiva diferente do mesmo tema.

\section{Referências}

Almeida, F. H. \& Melo-Silva, L. L. (2011). Influência dos pais no processo de escolha profissional dos filhos: uma revisão da literatura. Psico-USF (Impr.), $16, .75-85$.

Almeida, M. E. G. G \& Magalhães, A. S. (2011). Escolha profissional na contemporaneidade: projeto individual e projeto familiar. Rev. bras. orientac. prof, 12, 205-214.

Almeida, M. E. G. G \& Pinho, L. V. (2008) Adolescência, família e escolhas: implicações na orientação profissional. Psicol. clin., $20,173-184$.

Benevides-Pereira, A. M. T. \& Gonçalves, M. B. (2009). Transtornos emocionais e a formação em Medicina: um estudo longitudinal. Revista Brasileira de Educação Médica33, 10-23

Bock, A. M. B. (2007). A adolescência como construção social: estudo sobre livros escolares para pais e educadores. Psicol. Esc. Educ. (Impr) 11, 63-76.

Bohoslavsky, R. (1993). Orientação vocacional: a estratégia clínica. Martins Fontes.

Bussad, T. F. S. (2006). Reflexão sobre a vocação médica. In: Leitura com médicos: A educação da sensibilidade pela estética. PUC, Departamento de Letras, p. $80-100$

Carvalho, E. L. D. (2007). A escolha da profissão: um estudo sobre vocação médica. Dissertação de mestrado, Universidade Federal de Pernambuco. Recife, Pernambuco

Coelho, M. D. G. S. C., \& Matos, R. P. (2020). Perspectivas da formação técnica e inserção no mercado de trabalho: Um estudo em uma Instituição Pública Federal de Minas Gerais. Research, Society and Development, 9(1), e123911775-e123911775. https://doi.org/10.33448/rsd-v9i1.1775

Corrêa, R. D., Gonçalves, R. C. B., Oliveira, L. S. de, Silva, V. C. M., \& Ribeiro, M. M. F. (2016). Medicina como Nova Graduação: Motivações, Dificuldades e Expectativas. Revista Brasileira de Educação Médica, 40, 226-233. https://doi.org/10.1590/1981-52712015v40n2e02402014

Corsi, P. R., Fernandes, É. L., Intelizano, P. M., Montagnini, C. C. B., Baracat, F. I., \& Ribeiro, M. C. S. de A. (2014). Fatores que influenciam o aluno na escolha da especialidade médica. Revista Brasileira de Educação Médica, 38, 213-220. https://doi.org/10.1590/S0100-55022014000200008

Costa, J. R. B., Romano, V. F., Costa, R. R., Gomes, A. P., Alves, L. A., \& Siqueira-Batista, R. (2014). A transformação curricular e a escolha da especialidade médica. Revista Brasileira de Educação Médica, 38, 47-58. https://doi.org/10.1590/S0100-55022014000100007

Fernandes, D. C. (2006). Mitos familiares e escolha profissional: uma visão sistêmica. Psic: revista da Vetor Editora, 7, 99-100

Gomes, M. A. V. (2005). A expressão das emoções em contexto organizacional: catarse, contágio emocional e trabalho emocional: um estudo de caso. Dissertação (Mestrado em Recursos Humanos) - Faculdade do Minho, Braga. p. 76

Guedes, M. C. (2008). Women's presence in undergraduate and graduate courses: deconstructing the idea of university as a male domain. História, Ciências, Saúde-Manguinhos, 15, 117-132

Lara, L. D., Araújo, M.C.S., Lindner, V. \& Santos, V.P.L.S. (2005). O adolescente e a escolha profissional: compreendendo o processo de decisão. Arq. Ciênc. Saúde. Unipar, Umuarama, 9(1), 57-61

Maia, L. (2012). O conceito de meio técnico-científico-informacional em Milton Santos e a não-visão da luta de classes. Caminhos de geografia, 13, 29-41 
Martins, M. A., Silveira, P. S. P. \& Silvestre, D. (2013). Estudantes de Medicina e Médicos no Brasil: Números Atuais e Projeções. PROADI-SUS (Projeto Avaliação das Escolas Médicas Brasileiras, Relatório I), p.104

Moreira, S. N. T., Silva, C. A. N., Tertulino, F. F., Tertulino, F. M. F., Vilar, M. J. P., \& Azevedo, G. D. (2006). Processo de significação de estudantes do curso de medicina diante da escolha profissional e das experiências vividas no cotidiano acadêmico. Revista Brasileira de Educação Médica, 30, 14-19. https://doi.org/10.1590/S0100-55022006000200003

Nepomuceno, R. F. \& Witter, G. P. (2010). Influência da família na decisão profissional: opinião de adolescentes. Psicol. Esc. Educ. (Impr.), 14, 15-22.

Oliveira, J. D. (2017). Escolha profissional: uma visão humanista-existencial. Psicologia e saúde em debate, 4(1), 1-8. https://doi.org/10.22289/2446922X.V4N1A1

Oliveira, M. B. L. D. (2017). A escolha profissional. Temas em educação e saúde, 1. https://doi.org/10.26673/tes.v1i0.9842

Rego, R. M., Marques, N. A., Monteiro, P. C., Oliveira, C. L. B., Lins, N. A. A. \& Caldas, C. A. M. (2018). O perfil atual do estudante de Medicina e sua repercussão na vivência do curso. Pará Research Medical Journal, 2(1-4), e05. https://doi.org/10.4322/prmj.2018.005

Ribeiro, M. F., Saraiva V., Pereira P. \& Ribeiro, C. (2019). Escala de Motivação Académica: Validação no Ensino Superior Público Português. RAC, Maringá, $23,288-310$

Roth, S., Silva, S. \& Monteiro, S. (2014). Influências familiares na escolha profissional. Anais - II Congresso de Pesquisa e Extensão da FSG, 2. Saúde e Ciências Agroveterinárias - Resumo Expandido, p. 455-463

Santos, L. M. M. (2005). O papel da família e dos pares na escolha profissional. Psicol. estud., Maring10, 57-66

Sarriera, J. C., Silva, M. A., Kabbas, C., \& Lópes, V. B. (2001). Formação da identidade ocupacional em adolescentes. Estudos de Psicologia (Natal), 6, 27-32. https://doi.org/10.1590/S1413-294X2001000100004

Scheffer, M. C \& Cassenote, A. J. F. (2013). A feminização da medicina no Brasil. Revista Bioética21, 268-277, 2013

Shitsuka, R. (2018). Metodologia Da Pesquisa Científica. 119.

Sousa, I. Q., Silva, C. P., \& Caldas, C. A. M. (2014). Especialidade médica: Escolhas e influências. Revista Brasileira de Educação Médica, 38, 79-86

Souza, M. E. L. (2018). Formação médica e humanização. Tese de Doutorado, Psicologia Escolar e de Desenvolvimento Humano Instituto de Psicologia, Universidade de São Paulo, São Paulo, 2018

Souza, P. G. A., Pôrto, A. C. C. A., Souza, A., Silva, A. G., \& Borges, F. T. (2020). Perfil Socioeconômico e Racial de Estudantes de Medicina em uma Universidade Pública do Rio de Janeiro. Revista Brasileira de Educação Médica, 44. https://doi.org/10.1590/1981-5271v44.3-20190111.ING

Veras, R. M., Fernandez, C. C., Feitosa, C. C. M., \& Fernandes, S. (2020). Perfil Socioeconômico e Expectativa de Carreira dos Estudantes de Medicina da Universidade Federal da Bahia. Revista Brasileira de Educação Médica, 44. https://doi.org/10.1590/1981-5271v44.2-20190208 